\title{
Endobronchial lipoma*
}

\author{
ANTÔNIO MAURO BOF', ABRÃO RAPOPORT², LUIZ CARLOS PAIER', YARA LOPES DIAZ', \\ LUIZ CARLOS FILGUEIRAS LEIRO', ROBERTO RUBEN PANDO-SERRANO', \\ MÁRCIO ROGÉRIO ALCALÁ GOMES', EMÍLIO SCAFURA LOMONTE'
}

\begin{abstract}
Lipomas are benign neoplasms composed primarily of adipose tissue and may be located in various parts of the body. The case reported is that of a patient who sought medical assistance complaining of recurring pneumonia. After diagnostic procedures, including chest X-ray and computed tomography scan of the chest, endobronchial lesion with fat density was suspected. The diagnostic hypothesis was endobronchial lipoma. This hypothesis was confirmed after surgical intervention. The aim of this study was to report this case of endobronchial lipoma and to review the available literature on the subject.

Keywords: Pneumonia/complications; Recurrence; Bronchial neoplasms/surgery; Lipoma/surgery; Tomography, X-ray computed; Case reports
\end{abstract}

\section{INTRODUCTION}

Lipomas are relatively common benign neoplasms, of adipocytic origin. Lipomas can appear in any part of the body but are more commonly found in subcutaneous tissue. Clinically, lipomas are characterized by single or multiple nodular lesions that are firm and elastic in consistency. Lipomas are normally asymptomatic and are removed surgically, typically for aesthetic reasons. They are occasionally, although rarely, located in the thoracic cavity, affecting the bronchi, mediastinum, heart, lung parenchyma or pleura. ${ }^{(1)}$

Endobronchial lipomas are quite rare and, although histologically benign, may cause significant morbidity due to recurrent pneumonia caused by bronchial obstruction. ${ }^{(2)}$ With early diagnosis and appropriate treatment, serious pulmonary complications can be avoided. The present study aimed to report a case of endobronchial lipoma and to review the literature on the subject.

\footnotetext{
*Study carried out in the Department of Pulmonology and Thoracic Surgery of the Heliópolis Hospital, São Paulo, São Paulo, Brazil

1. Thoracic Surgeon in the Department of Pulmonology and Thoracic Surgery of the Heliópolis Hospital. Dr. Salvador Mercurio Netto Study Center, São Paulo, São Paulo, Brazil.

2. Coordinator of the Graduate Program at the Heliópolis Hospital, São Paulo, São Paulo, Brazil.

Correspondence to: Antônio Mauro Bof. Rua: José Alves, 161 - CEP: 29075-080, Goiabeiras, Vitória - ES. E-mail:

maurobof@ig.com.br

Submitted: 9 March 2005. Accepted, after review: 10 May 2005.
} 


\section{CASE REPORT}

A 66-year-old patient was referred to the thoracic surgery outpatient clinic for investigation of recurrent episodes of pneumonia for two years. Upon clinical and physical examination, the patient presented good general condition, mild dyspnea, normal skin color and normal blood gas analysis. In the thorax, the patient presented underlying fluid density and reduced breath sounds in the left lung base. A simple chest Xray, taken upon admission, revealed left lower lobe opacity, with reduced lung volume and left mediastinal deviation, partial left lower lobe atelectasis and scoliosis of the thoracic vertebrae. A computed tomography scan of the chest revealed a low density image, characteristic of fat and obstructing the left main bronchus. The diagnostic hypothesis was recurrent pneumonia due to the bronchial obstruction caused by a lesion with fat density suggestive of lipoma.

The treatment chosen was left thoracotomy followed by bronchotomy to excise the lesion, interrupted bronchial suture with separate stitches (using polypropylene sutures) and chest wall closure (Figure 1). The surgical sample removed presented a yellowish nodule of elastic consistency with bosselated areas (Figure 2). Under microscopy, we found bronchial mucosa presenting, in the chorion, a tumor formed of mature adipose tissue with glands belonging to the region proper (Figure 3). The postoperative period was uneventful. The patient was discharged on the seventh postoperative day and was asymptomatic after four years of outpatient follow-up.

\section{DISCUSSION}

The patient in question was referred to the thoracic surgery outpatient clinic for diagnostic investigation of recurrent episodes of respiratory infection. Although various etiologic factors were investigated, it is of note that the pneumonia always occurred on the left side, which also led us to consider endobronchial lesion as the primary cause of the clinical profile.

Endobronchial lipomas are benign tumors and account for $0.1 \%$ to $0.5 \%$ of all lung neoplasms. In a review of the literature, 109 reported cases of

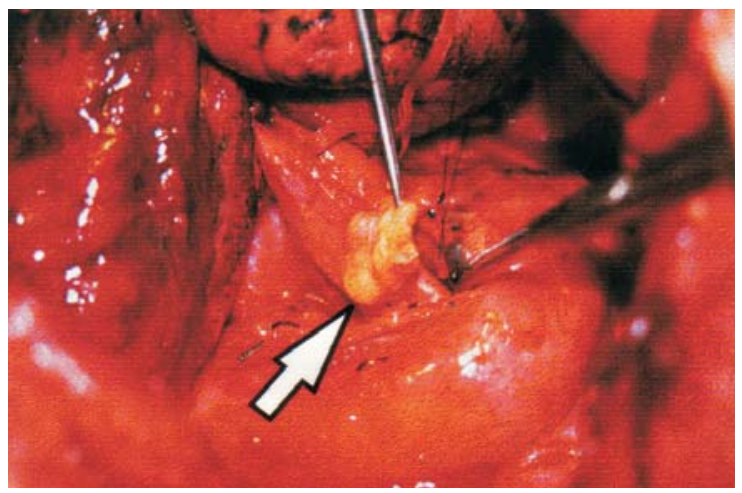

Figure 1 - View of the cavity: the arrow shows excision of the lipoma of the left main bronchus. The arrow is over the aorta.

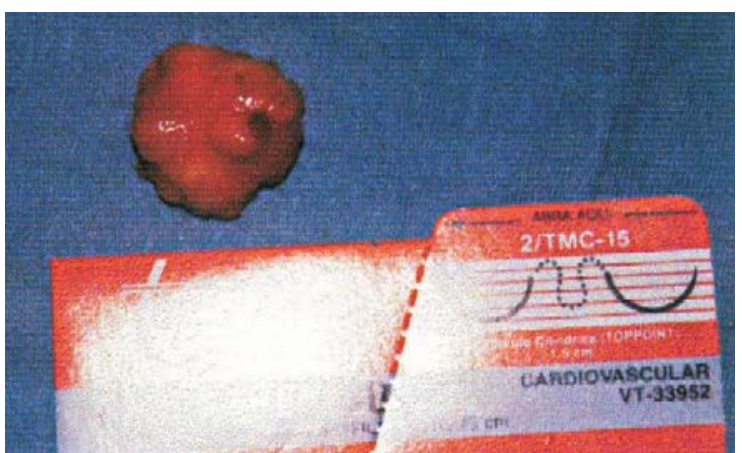

Figure 2 - Surgical sample: bosselated nodule measuring $2.5 \times 1.5 \times 1.3 \mathrm{~cm}$

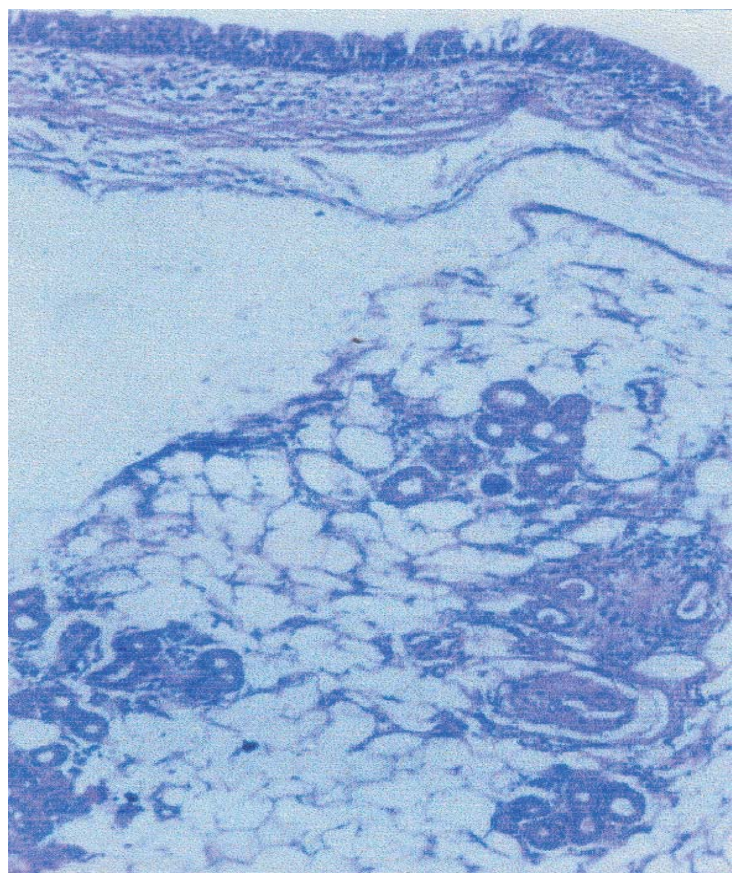

Figure 3 - Histopathological study revealing a lipoma 
endobronchial lipomas were found. ${ }^{(3)}$ In a study of 6500 fiberoptic bronchoscopies, only 4 cases of endobronchial lipomas (0.06\%) were found among the 210 benign tumors diagnosed $(3.23 \%) .{ }^{(4)}$ Since lipomas are rare, it is difficult to know the exact prevalence rate.

Endobronchial lipomas occur more frequently from the fifth and sixth decade of life onward, being more prevalent among males and obese individuals. ${ }^{(5)}$ Symptom presentation is largely dependent on the degree of airway obstruction. Lipomas can present as cough, dyspnea or recurrent pulmonary infection. The pulmonary lesions, predominantly located distally, can be irreversible and might be clinically mistaken for bronchial carcinoid tumors. ${ }^{(6)}$ Since endobronchial lipomas are relatively avascular, hemoptysis is a rare symptom, occurring in less than $25 \%$ of cases. ${ }^{(2)}$

Although endobronchial lipomas generally initiate in the submucosa, they can also grow in cartilage, having a ground glass appearance and a peribronchial component. Transbronchial ("iceberg") development is less common, and only six cases have been reported in the literature. ${ }^{(7)}$ These neoplasms consist of lobes formed by mature fat cells, separated by fibrous septa and surrounded by a thin, also fibrous, capsule.

In the differential diagnosis of the causes of bronchial obstructions, chondromatous hamartoma and other types of intrapulmonary hamartomas, as well as leiomyoma, should be considered ${ }^{(8-9)}$ In some cases, there might be concomitant neoplastic disease, principally primary pulmonary tumor. ${ }^{(10)} \mathrm{In}$ a recent review of the Japanese literature, it was shown that 64 cases of endobronchial lipoma were reported between 1971 and 2001, accounting for $0.1 \%$ to $0.5 \%$ of all pulmonary tumors. ${ }^{(11)}$

In the search for endobronchial lesions of adipose origin, chest $\mathrm{X}$-rays are nonspecific. Therefore, computed tomography scans of the chest are currently important since they show the exact location of the lesion and allow evaluation of the subjacent parenchyma and of the lesion density, which is low. ${ }^{(12-13)}$ In the case of our patient, the lesion presented a density of -150 Hounsfield units, which is the specific density of fat. Through the use of magnetic resonance imaging, we can accurately determine the morphological characteristics of the mass found, with a hypersignal on the T1-weighted images and an intermediate signal on the T2-weighted images. ${ }^{(14)}$ Fiberoptic bronchoscopy is important since it identifies the lesion location and facilitates the collection of histopathological evidence through biopsy. Our patient was treated in a public hospital and, for technical and logistical reasons, it was not possible to carry out a fiberoptic bronchoscopy at the time. The definitive diagnosis is made through histological analysis of the lesion, which will reveal lobes of mature fat cells, either partially or totally surrounded by a fibrous capsule.

The treatment of these tumors must be the most conservative possible. If there is no bronchial or parenchymal lesion around the tumor, and there is histopathological confirmation of the diagnosis, endoscopic resection is the treatment of choice. The technique that uses a yttrium-aluminum-garnet laser is currently the treatment of choice in cases of benign endobronchial tumors and presents a low rate of complications (pneumothorax or mediastinal emphysema), on the order of $2 \%{ }^{(15)}$ Resection with electrocautery is a useful alternative to treat some types of intramural tumors, including lipoma. ${ }^{(16)}$ Thoracotomy is indicated when there is evidence of bronchiectasis, atelectasis or obstructive pneumonia. ${ }^{(7,12)}$

In the case reported, the therapy chosen was thoracotomy because there was no other way of resolving the case in a public hospital, and the patient could not afford to undergo endoscopic resection in a specialized clinic. At the time this case report was being prepared, the patient, who remained asymptomatic four years after the surgery, was receiving outpatient follow-up treatment and was working regularly.

In summary, endobronchial lipomas are rare benign tumors whose symptomatology is dependent on the degree of bronchial obstruction. Computed tomography scans of the chest and fiberoptic bronchoscopy are the most widely-used diagnostic methods, and diagnosis is defined through histopathological examination. Under specific conditions, endoscopic resection is the treatment of choice. However, when endoscopic resection is unfeasible, thoracotomy is indicated. Since the lesion is benign, the treatment should be the most conservative possible. 


\section{REFERENCES}

1. Teran Santos J, Campo Luarte J, Rodrigues Pascual L, Garcia Munoz JP, Gallo Marin F, Viejo Banuelos JL. [Pleural lipomas: their diagnosis by computed axial tomography]. Rev Clin Esp. 1990;187(40):203-4. Spanish.

2. Simmers TA, Jie C, Sie B. Endobronchial lipoma posing as carcinoma. Neth J Med. 1997;51(4)143-5.

3. Hirata T, Reshad K, Itoi K, Muro K, Akiyama J. Lipoma of the peripheral lung: a case report and review of the literature. Thorac Cardiovasc Surg. 1989;37(6):385-7.

4. De Abajo C, Morato A, Lázaro L, Gallo F, Pueyo A, Viejo JL. [Endobronchial lipomas. Apropos of 4 cases]. Rev Pneumol Clin. 1996;52(6):373-7. French.

5. Box K, Kerr KM, Jeffrey RR, Douglas JG. Endobronchial lipoma associated with lobar bronchiectasis. Respir Med. $1991 ; 85(1): 71-2$.

6. Celik G, Kaya A, Ozdemir 0, Ozdemir N, Dizbay Sak S, Alper D. Endobronchial lipoma: a case report. Tuberk Toraks. 2003;51(4):432-5.

7. Drira 1, Souissi R, Horchani H, Kilani T, Labbene N, Chebbi ML [Endo-bronchial lipoma. A propos of a case]. Rev Pneumol Clin. 1995;51(4):247-9. French.

8. Matsuba K, Saito T, Ando K, Shirakusa T. Atypical lipoma of the lung. Thorax. 1991;46(9):685.

9. Scarpinella-Bueno A, Santoro ll. Leiomioma intrabrônquico: relato de um caso. J Pneumol. 1995;21(4):199-200.
10. Kamiyoshihara M, Sakata K, Otani Y, Kawashima 0, Takahashi T, Morishita Y. Endobronchial lipoma accompanied with primary lung cancer: a report of a case. Surg Today. 2002;32(5):402-5.

11. Muraoka M, Oka T, Akamine S, Nagayasu T, lseki M, Suyama N, et al. Endobronchial lipoma: review of 64 cases reported in Japan. Chest. 2003;123(1):293-6.

12. Mata JM, Cáceres J, Ferrer J, Gómez E, Castaner F, Velayos A. Endobronchial lipoma: CT diagnosis. J Comput Assist Tomogr. 1991;15(5):750-1.

13. Liu KL, Chang YC, Lee YC, Chen SJ, Lee WJ. Computed tomography diagnosis of post-obstructive atelectasis by an endobronchial lipoma. J Formos Med Assoc. 2004;103(2): 148-50.

14. Rodriguez E, Pombo F, Gallego C, Otero 1. Endobronchial lipoma. Computed tomography and magnetic resonance. Chest. 1994;105(5):1628.

15. Shah H, Garbe L, Nussbaum E, Dumon JF, Chiodera PL, Cavaliere S. Benign tumors of the tracheobronchial tree. Endoscopic characteristics and role of the laser resection. Chest. 1995;107(6):1744-51.

16. Huisman C, Van Kralingen KW, Postmus PE, Sutedja TG. Endobronchial lipoma: a series of three cases and the role of eletrocauter. Respiration. 2000;67(6):68992. 